\title{
Golf Courses' Water Use and Conservation Practices in Miami-Dade County 1
}

\section{Rafael Muñoz-Carpena, Jonathan H. Crane, Glenn \\ Introduction and background}

The Miami-Dade County golf course industry has assets (e.g., land, vehicles and equipment, irrigation systems, and golf-owned buildings and equipment) in excess of $\$ 1.4$ billion dollars and generates sales of over $\$ 288$ million dollars annually (Haydu and Hodges, 2002). The industry employs about 2,364 people on 48 golf courses and there are about 8,400 acres of maintained turf. All golf courses in Miami-Dade County are irrigated to some extent (C. Yurgalevitch, personal communication).

Some of the major issues facing the golf course industry in Florida include marketing, adjacent land use planning, water and fertilizer management, pests and diseases, natural disaster avoidance and mitigation, and sustainable cultural practices. Due to the on-going Everglades and Biscayne National Park restoration projects, water and fertilizer management practices for the golf course industry will become critical components of its sustainability.

Water use, management, and quality are major issues in Florida's Miami-Dade County where periods of excessive rainfall (flooding) and extended dry spells (drought) are experienced occasionally. Water use practices (e.g., irrigation and fertilizer management) can potentially affect the water quality of the Biscayne Aquifer and Biscayne Bay. However, water conservation practices by the Miami-Dade County golf course industry are largely undocumented.

This fact sheet reports water conservation trends from golf course managers based on a recent extensive survey carried out in Miami-Dade County.

\section{Survey and analysis methodology}

The survey involved a random sample of 29 golf course managers that were selected from mailing lists obtained from the Miami-Dade County/IFAS Cooperative Extension Service and golf course organizations in Miami-Dade County. This sample represented $60 \%$ of the total potential population.

The survey instrument contained questions concerning current water consumption and irrigation

1. This document is Fact Sheet ABE348, one of a series of the Agricultural and Biolgoical Engineering Department, Florida Cooperative Extension Service, Institute of Food and Agricultural Sciences, University of Florida. Published January 2004. Please visit the EDIS Web site at http://edis.ifas.ufl.edu.

2. R. Muñoz-Carpena, Asst. Prof., Hydrologist, and J.H. Crane, Prof., Tropical Fruit Crops Specialist, Tropical Research and Education Center, Homestead, FL; G.D. Israel, Agricultural Education and Communication Dept., Gainesville, FL and; C. Yurgalevitch, Commercial Landscape Extension Agent, Miami-Dade County Cooperative Extension Service, Homestead, FL: Cooperative Extension Service, Institute of Food and Agricultural Sciences, University of Florida, Gainesville, 32611

The Institute of Food and Agricultural Sciences (IFAS) is an Equal Employment Opportunity - Affirmative Action Employer authorized to provide research, educational information and other services only to individuals and institutions that function without regard to race, creed, color, religion, age, disability, sex, sexual orientation, marital status, national origin, political opinions or affiliations. For information on obtaining other extension publications, contact your county Cooperative Extension Service office. Florida Cooperative Extension Service / Institute of Food and Agricultural Sciences / University of Florida / Larry R. Arrington, Interim Dean 
practices, motivations for their adoption by managers, issues affecting water use, drought and flooding experience, and water management. Questions related to when they first started managing and the size of the golf course were added to gain a perspective of changes in the area with time.

The survey procedures were tailored to maximize golf course manager participation (Dillman, 2000). Each potential respondent received a letter informing him or her of the purpose of the survey. Two weeks later the surveys were sent out, and telephone follow-up was done 4 and 8 weeks later. The survey protocol was designed to collect enough responses for statistical analysis of the influence of the economic, technical, and sociological factors on water conservation practices in the area. The survey data were analyzed using SAS software FREQ and MEANS statistical procedures (SAS, 1999).

\section{Survey results}

\section{Background}

Although an initial random sample of 29 surveys was sent out, some managers could not be contacted. Of the 23 managers who were in the reachable sample, only 8 returned usable surveys. The survey response rate was $35 \%$, representing one sixth of the golf course acreage. Mail-back survey response rates of 10 to $50 \%$ are common and typically may be as low as 20\% (Donan et al., 2000; Nachmias and Nachmias, 1976; Neuman, 1997). Because of the low survey participation, responses will be reported based on the number of managers with percentages placed in parentheses.

The mean land area for golf courses was 113 acres with $6(69 \%)$ of the respondents managing and $2(31 \%)$ owning the golf course. All the golf course land areas were reported to be irrigated to some extent.

\section{Changes in irrigation technology and water resources}

Golf courses use solid set and/or pop-up irrigation systems exclusively (Fig. 1). These high volume systems are modified to allow either the insertion and removal of the sprinkler pipes or are pop-up systems so that they do not interfere with the golf game. In both cases the irrigation system is capable of covering large areas. Pop-up systems have sprinkler heads that emerge above ground by water pressure and submerge below ground level once the water is turned off.

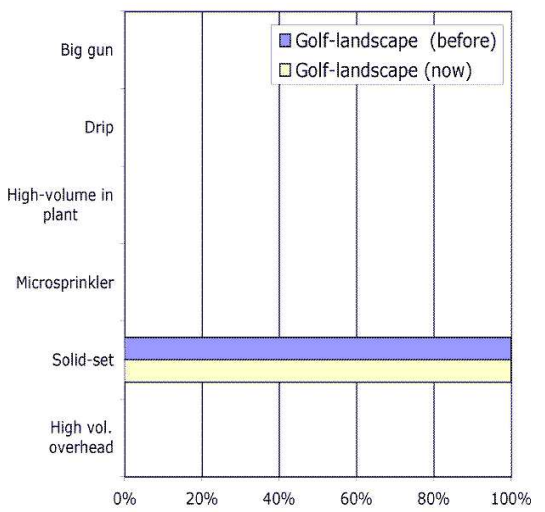

Figure 1. Changes in irrigation systems used by golf course managers with time. The term "before" denotes the irrigation system used when the manager first started managing and "after" denotes the current irrigation system used.

There have been changes in irrigation system technology, and soil water content monitoring during the past 11 years, which is the average time survey respondents have been managing golf courses. Generally, irrigation efficiencies have been improved in golf course operations. This is due to technological improvements in devices that monitor water use and by the use of soil water content monitoring devices that enable managers to reduce leaching and apply water based on golf course landscape needs. For example seven $(88 \%)$ of the golf course managers indicated they used tensiometers to monitor soil water content.

The sources of water varied among golf course operations, two (25\%) reported using capped/cased wells, one (13\%) open/uncased wells, and five (63\%) using city water (Fig. 2).

\section{Flooding and drought frequency}

Drought was reported by five (63\%) of the golf course operators. Of those managers reporting drought, $6(75 \%)$ indicated there was damage to the landscape, and three (38\%) reported a loss of income. The large number of managers reporting they 


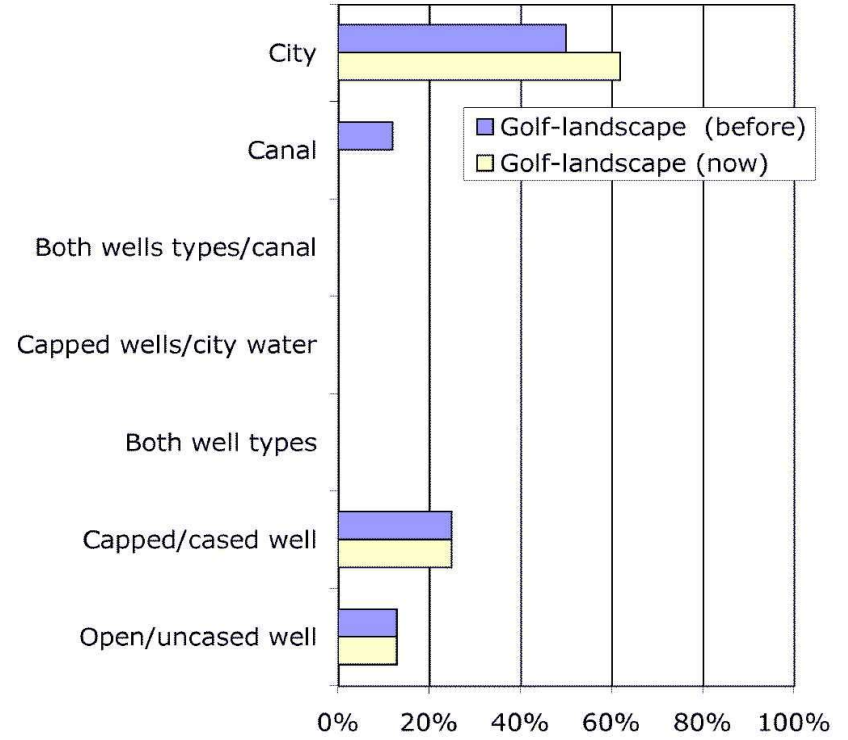

Figure 2. Changes in water sources used by golf course managers with time. The term "before" denotes the irrigation system used when the manager first started managing and "after" denotes the current irrigation system used.

experienced drought may be because of regional water restrictions placed on water users during periods of drought. Three (33\%) of the managers reported their golf course experienced flooding during the last five years. Of those managers reporting flooding, one indicated there was damage to the landscape, and two reported a loss of income.

\section{Water conservation practices, and motivations for adopting them}

The survey included questions on the adoption of water conservation practices, and motivations for adopting them. Golf courses use solely some type of high volume sprinkler system (Fig. 1). However, three $(38 \%)$ reported trying to limit the area they irrigate. Interestingly, three (38\%) reported trying to limit their need for irrigation by incorporating drought tolerant plant material in the landscape with one mangager planning to do so in the future. Seven managers $(88 \%)$ reported utilizing mulch in the golf course landscape. Seven (88\%) monitor soil water content and weather data to assist in irrigation management, 6 (75\%) check water pump efficiency, and seven (88\%) utilize water meters and keep records of water use. Only one manager reported using the services of the Mobile Irrigation Lab (MIL) and another one plans to do so in the future. This service is designed to assess the water and energy use efficiency of irrigation systems at no charge to producers. Recommendations for repairs and/or upgrades are provided in an effort to increase irrigation efficiency and conserve water. Interestingly, three (38\%) of the golf course managers plan on capturing rain water for washing equipment in the future and one plans to capture equipment wash water and reuse it for other purposes. All golf course managers indicated they irrigate at night or early morning.

The three most common motivations for conserving water were savings in water, time, and money. The primary motivation varied with each water conservation practice. For example, of the seven $(88 \%)$ golf course managers that utilize water meters and record water use, three $(38 \%)$ cited money as their primary motivation. In contrast, the six $(75 \%)$ managers that check water pump efficiency indicated either water, time, money, or a combination of the three at the $25 \%$ level as for their motivation. Of the seven $(88 \%)$ of the managers that monitor soil water content, the primary motivation was water and money savings (40\%). Money savings only was listed as the primary motivation by only two of those responding.

\section{Conclusions and challenges ahead}

Our results generally show an increase in the adoption of water conservation practices in the Miami-Dade golf course industry in the last 11 years. This includes utilization of drought tolerant plants (38\%), increased use of mulch (88\%), monitoring soil water content (87\%), and checking water pump efficiency $(77 \%)$ to name of few. The main reason for adoption of water conservation practices varied by water conservation practice, although the most consistently given reasons were water and money savings.

In spite of these positive findings, there remain important educational challenges to optimize water use while protecting the environment (Muñoz-Carpena et al., 2003). Improvements are needed in five major areas: 
1. Development of new or improved water delivery systems that do not interfere with the golfing game but decrease water use. Specifically, low volume-high frequency localized systems should be favored where possible (e.g. landscape areas).

2. Improvements in water management practices including record keeping, equipment maintenance, use of soil water content monitoring devices, and periodic irrigation evaluation by the Mobile Irrigation Lab.

3. Grouping of landscape plants with similar watering needs coupled with well designed irrigation blocks, and introduction of drought tolerant plants, (e.g., use of "Florida landscape" plant material).

4. Protection of water sources by phasing out open/uncapped wells in favor of increased use of capped and cased wells or city water sources.

5. Adoption of runoff and rainfall reuse water systems where feasible.

\section{Literature cited}

Dillman, D.A. 2000. Mail and Internet Surveys: The Tailored Design Method. John Wiley and Sons, New York.

Donan, A.H., R. Kreutzwiser, and R. de Loë. 2000. Rural water use and conservation in southwestern Ontario. J. Soil and Water Conservation 55:161-171.

Haydu, J.J. and A.W. Hodges. 2002. Economic impacts of the Florida golf course industry, Econ. Information Report EIR 02-4. Food and Resource Economics Dept., Fla. Coop. Ext. Service, Gainesville, Fla. P. 34.

Muñoz-Carpena, R., J. H. Crane, G.D. Israel and C. Yugalevitch. 2003. Water Conservation Survey of Miami-Dade County Agricultural and Golf Course Commercial Water Users. Proc. Fla State Hort. Soc. 116:(in press).

Nachmias D. and C. Nachmias. 1976. Research Methods in the Social Sciences. St. Martins Pres, New York.
Neuman, L.W. 1997. Social Research Methods: Qualitative and Quantitative Approaches. 3rd ed. Allyn and Bacon Publishers, Boston.

SAS Institute Inc. (1999). SAS 8.01 [Computer software]. Cary, NC: SAS Institute Inc. 